\title{
Exvotos a santos y patronos: el poder de las imágenes sagradas
}

\author{
Martha Marielba Herrera Reina \\ Antropóloga e investigadora
}

\section{A manera de introducción}

En El Salvador del siglo XXI, muchos cultos a imágenes sagradas, cristianas o no, son el reflejo de las necesidades espirituales, físicas y materiales de diferentes creyentes que en cualquier día del año pueden solicitarles ayuda. Estas peticiones, según registros eclesiásticos, surgieron desde el siglo XVI o el XVII a partir de los acuerdos del Concilio de Trento $^{1}$ en el que se mencionan, entre otros: la intercesión e invocación de los santos y sus imágenes; la difusión del marianismo; la devoción a los santos, ángeles y almas del purgatorio; las fiestas, romerías y procesiones. Esto implica la conformación de santuarios, conservar imágenes de Cristo, de la Virgen María y otros santos en los templos; uso del arte para instruir y confirmar la fe, en donde se utilizarían ejemplos de los santos y los milagros que se realizaron por su intercesión (Pastor, 1996. En Roselló, 1998, p. 8). De esta forma se establecen, a partir de la Iglesia-Institución, estas nuevas formas de cristianismo que se difundieron por todos los lugares conquistados por los europeos.

En la Nueva España y el Reino de Guatemala, las órdenes religiosas establecidas tuvieron, entre otras, la misión de fundar y construir templos dedicados a diferentes santos, con el fin de lograr que se llegara a la divinidad a través de las imágenes, mismas que debían servir como ejemplo de vida cristiana. Esta implantación de diversos personajes santificados, con el correr del tiempo, llegó a convertirse en cultos que se desarrollaban en espacios públicos y privados, permitiendo a los fieles tener un contacto directo con las imágenes a las que rinden cultos particulares, cada uno con sus diferentes expresiones de fe.

Estas merecen una aproximación desde la antropología. Por tal razón, este artículo pretende abordar y proponer su tipificación. En este caso, enfocada únicamente a exvotos, entendiéndolos como la materialización del hecho religioso que obliga a los seres humanos a expresar la satisfacción de la petición y cumplimiento de la promesa por un milagro ocurrido. Esto, a partir de exploraciones etnográficas realizadas desde el año 2011 al 2013 en el actual territorio salvadoreño.

1 Concilio católico ecuménico celebrado a petición del rey Carlos V, entre los años 1545 a 1563, ante el problema religioso luterano y problemas políticos que amenazaban el reinado y a la Iglesia católica. 


\section{Promesas de fe y resolución de problemas}

Desde la antropología de las creencias, el abordaje de este tipo de manifestación religiosa popular lleva a definirlo como la expresión de fe de los sectores populares a través de un complejo mundo de creencias y prácticas religiosas que ofrecen la solución a los problemas de diferentes sectores sociales; se vincula con santuarios, peregrinaciones, peticiones y gratitudes, es decir, con diversas formas de culto a los santos locales y las variadas manifestaciones de culto y de folclore.

La palabra exvoto viene del latín ex voto y significa “por voto”. Estas expresiones se orientan a diversas situaciones en las que los creyentes solicitan la resolución a problemas como enfermedades y epidemias, accidentes, desastres naturales, sismos, erupción de volcanes, guerras, agresiones violentas, viajes, pérdida o búsqueda de trabajo; la emigración hacia países lejanos o desconocidos; los reencuentros familiares y un sinfín de elementos más (García Curado, 2011). Estos objetos sirven específicamente para manifestar el agradecimiento por un don o bienestar concedido por parte de un agente poderoso de orden metasocial, hacia actores (individuales y/o colectivos) intramundanos (González, 1986). Se trata, entonces, de intercambios realizables en un comercio de fe entre lo sagrado y lo humano, donde la imagen del santo es la vía directa para obtener una respuesta o un favor sagrado que adquiere una connotación social en cuanto a un hecho comunitario que se comparte y vive con el resto de creyentes, aunque, vale decir, este universo comunitario trasciende las fronteras.

Estudios acerca de estas expresiones populares son muy escasos en El Salvador. La tipología propuesta está basada en investigaciones realizadas en México, que ofrecen una luz a la comprensión del mismo fenómeno religioso. Según González (1996), los exvotos se concentran en dos tipos:

a) es considerado un objeto de uso que ha estado en contacto directo con la intervención milagrosa, y por ello cumple una función simbólica especial, por ejemplo, un rosario, agua bendita u otros objetos considerados sagrados y que pueden resolver problemas físicos;

b) es una representación (plástica, escrita, fotográfica o pictórica) expresamente realizada para comunicar a otros el milagro. Este es el caso de la tipología que se aborda en este estudio, la que tiene elementos que pueden ser resignificados por los devotos, porque, al final de todo, es la gente misma la que los lleva a ese nivel sagrado.

Estos elementos de la religiosidad popular generalmente están alrededor de las imágenes de los santos o patronos. Estos pueden variar de tamaño y advocación; sin embargo, siempre están llenos de flores, objetos personales y velas, que están dispuestos a sus pies, en los laterales o en la misma imagen, y que son el signo de los milagros otorgados por aquellos. Hay algunas imágenes que son más populares que otras. Entre ellas, vemos a San Judas Tadeo (patrono de los imposibles), la virgen de Guadalupe y el Santo Niño de Atocha, estos se vuelven un canal que permite la relación íntima entre la divinidad y el ser humano. El culto a una imagen determinada proporciona, aparentemente, 
cierta cohesión y solidaridad social. Además, los devotos experimentan un espíritu comunitario; un sentimiento de gran solidaridad e incluso de igualdad y proximidad social. Estos espacios de prácticas rituales se ven envueltos en el plano social y cultural, en ocasiones también con lo nacional y económico. Estos ritos desempeñan un papel de enlace entre lo sobrenatural y lo divino; lo humano y lo práctico (Portal; en Fernández Poncela, 2009).

Castilla retoma de Prat (2011) que en estas expresiones, existen tres constantes que se repiten en todos los exvotos:

a) Un individuo que en circunstancias difíciles promete un regalo a la divinidad a cambio de la obtención de un favor.

b) El individuo, por convencimiento empírico o psicológico, considera que la divinidad ha satisfecho su petición.

c) El individuo ofrece ceremonialmente el regalo prometido, haciendo constar públicamente que ha cumplido su voto. Así, ofrecido el exvoto, el individuo considera que ha liquidado sus deudas con el ser sagrado y pone fin al pago al que voluntariamente se había comprometido.

Los exvotos dan a conocer las peticiones y favores recibidos por los santos. Estos tienen un esquema fijo: datos personales del oferente, relato escueto del motivo del exvoto, referencia a la persona que realiza la súplica, fecha exacta de la ejecución del exvoto, ser sobrenatural a quien se dirige la invocación de auxilio, fórmula de petición, explicitación del favor recibido, lugar donde transcurren los hechos ${ }^{2}$ Cada uno de ellos ayuda a comprender diferentes elementos de los sectores sociales que los solicitan, motivos de petición, sacrificios realizados, temporalidad y ubicación del hecho religioso.

Fernández Poncela identifica que este universo religioso, además, adquiere una connotación social. Estas prácticas proporcionan una aparente cohesión y solidaridad social. Además, los devotos experimentan un espíritu comunitario; un sentimiento de gran solidaridad e incluso de igualdad y proximidad social. Muchas veces las vemos más fácilmente en cultos públicos de mayores dimensiones, por ejemplo, las peregrinaciones a centros religiosos, como iglesias y grutas. Aquellos se ven envueltos en el plano social y cultural, así como también en el económico. Estas formas de búsqueda de ayuda en algunas ocasiones surgen ante carencias y necesidades de salir adelante, en la sanación de una enfermedad, entre otras. En cualquiera de los casos, los creyentes practican rituales que desempeñan un papel de enlace entre lo sobrenatural y lo divino; lo humano y lo práctico. Son parte de la reproducción social, un mecanismo de suma e inclusión (Portal; en Fernández Poncela, 2009: 93). En este sentido, el vínculo comunitario religioso se fortalece al compartir y reproducir estas expresiones religioso- culturales, que muchas veces han sido transmitidas de generación en generación y que adoptan nuevas formas con el paso del tiempo. Estas se vuelven válidas desde el momento en que la comunidad las reproduce.

2 Texto en línea, tomado de: Diccionario de mitos y leyendas. Equipo NAyA. http://www.cuco. com.ar/exvotos.htm 
Lo que acá se propone tiene como base el estudio realizado en México por el investigador Jorge A. González (1986), denominado "Exvotos y retablitos, religión popular y comunicación social en México". Por la realidad social puede aplicarse esta tipología y generarse una aproximación a la temática de los exvotos en El Salvador.

\section{Propuesta de tipología de exvotos en EI Salvador}

Tomando en cuenta los aportes de diversos investigadores de la temática de la religiosidad, para el caso de El Salvador, se encuentran exvotos que son comunes al resto de la región centroamericana y que son el testimonio de los milagros realizados por los santos a los que se acude. Sin embargo - como se mencionó anteriormente-, cualquier objeto puede llegar a convertirse en un exvoto. De esta forma, se pueden encontrar los siguientes:

a) Milagritos: objetos a escala figurativos de la gracia obtenida (partes anatómicas o figuras humanas, casas, animales, vegetales, vehículos, flores, otros), generalmente hechos de metal, cera y otros materiales, dependiendo de lo solicitado.

En El Salvador, la mayoría de estos milagritos son de materiales como la cera y el metal. Generalmente se los ubica en dos espacios dentro de los santuarios; uno de ellos lo comparte con la imagen del santo; algunos los cuelgan o los ponen en las vestimentas de los santos; los cuelgan o colocan en sus manos. Esto en el caso que se les permita esa cercanía; si no es así, las imágenes anatómicas de cera son colocadas en canastas a los pies de la imagen o son consumidas por el fuego en los muebles metálicos destinados a las velas.

Los milagritos de cera son retirados de las imágenes, pues así lo dispone el párroco encargado de la iglesia, mientras los metálicos se mantienen en los lugares que los petidores los han colocado. Muchos

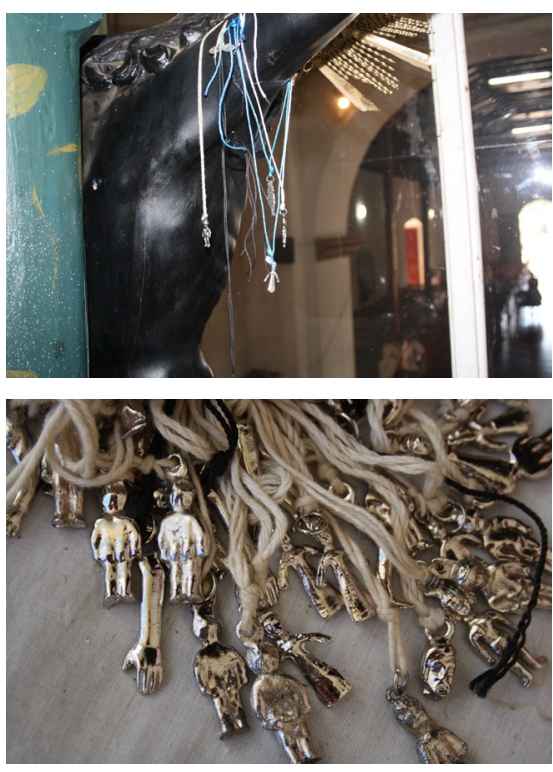

Figuras 1 y 2. Milagritos de cera y metal, asociados a sanaciones
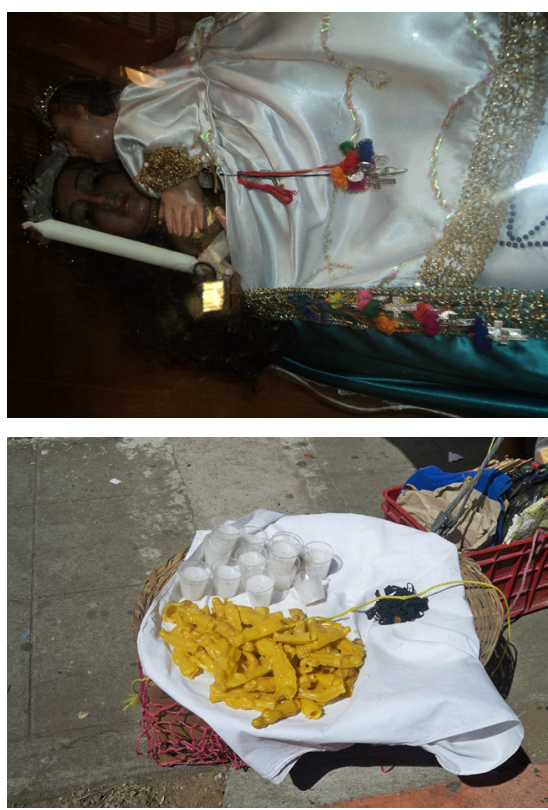

Figuras 3 y 4. Milagritos colgados en la imagen de la Virgen María y exvotos de cerca a la venta en las afueras de la iglesias. Fotografía: Academia Salvadoreña de la Historia.2012. 
ejemplos de estos últimos pueden verse en diferentes templos católicos del país; entre ellos, los registrados en Conchagua, Ereguayquín, Juayúa y Concepción Batres.

b) Resignificados. Estos resaltan elementos representativos de diversos materiales, que varían de formas y tamaños, entre ellos, diplomas o títulos (por logros académicos), gorras, camisetas deportivas, ramos de novias o quinceañeras (por alianzas matrimoniales o cumplimiento de los quince años de edad), ramos de flores plásticas, muletas o aparatos ortopédicos o médicos, yesos, vendas elásticas (por sanaciones), entre otros.

Cada uno de ellos tiene un significado particular, especial para quien lo ofrece como agradecimiento. Por esto, no es sencilla su interpretación. En ese caso, debe (si es posible) entrevistarse al creyente para comprender dicho significado. En el registro fotográfico, una de las muestras más representativas fue encontrada en la basílica Sagrado Corazón, en el centro de San Salvador; uno de los altares con mayores exvotos allí es el de San Judas Tadeo, que concede milagros "imposibles". Otras se encuentran en los altares laterales de la misma iglesia, así como en Chalatenango y otras en el territorio salvadoreño. Las diversas expresiones van desde gorras de policía, medallas, pulseras y ramos. Cada uno de ellos fundido en un universo donde lo subalterno está presente; además, son objetos que han pertenecido a la persona por la que se le solicita el milagro a la imagen sagrada.
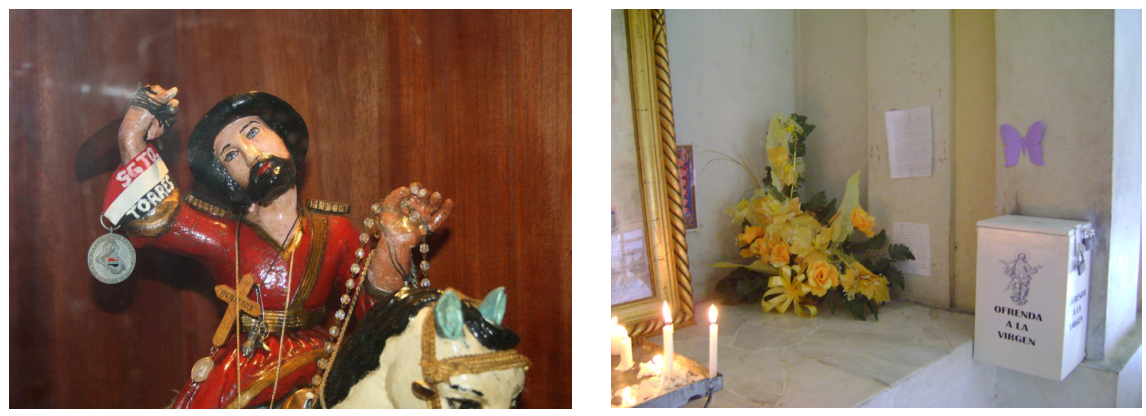

Figuras 5 y 6. Objetos personales como medallas, camándulas y ramos son ofrecidos a los santos como pagos o peticiones por el milagro recibido. Fotografías: Marielba Herrera Reina. 2011.

c) Discursivos. Son los objetos en los que se alude al milagro de manera escrita o gráfica en una base de papel, mármol, plástico o resina.

Generalmente, es común encontrarlos en grabados sobre mármol o piedra, así como cartas o frases escritas manualmente sobre papel común. En la zona norte de El Salvador, se ha podido registrar un sinfín de cartas personalizadas que agradecen a los diferentes santos que se encuentran resguardados en los templos. El contenido de la escritura refleja una relación personal y directa con el santo, siendo este el canal directo de agradecimiento. Sin embargo, hay templos que presentan estos exvotos gráficos en los que los creyentes dibujan lo que están agradeciendo o a los santos a los que acudieron para obtener el milagro, por ejemplo, en una página de papel dibujaron un pie, porque el niño había sido sanado gracias a san Jerónimo Doctor; en el papel, el niño agradece por 
medio de la imagen del área sanada por el milagro. Este podría ser una variante de los antiguos exvotos en lámina que según algunos entrevistados se realizaban, pero que con el tiempo se perdió esa práctica. Muchas de las cartas son escritas en papeles sencillos rayados de cuaderno o libretas. Esto evidencia la condición social donde surgen estas peticiones.
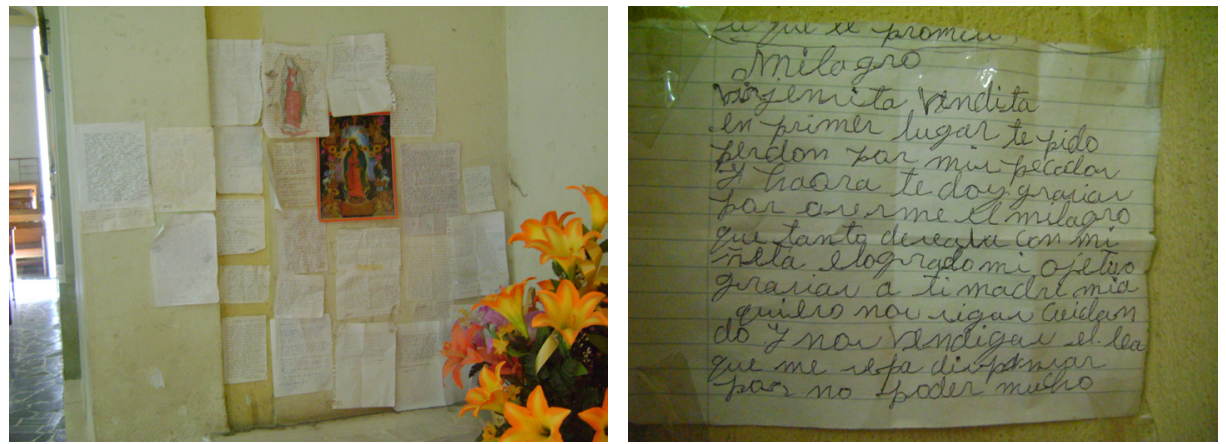

Figuras 7 y 8. Exvoto de la Virgen de Guadalupe y una carta personalizada a la Virgen María. Fotografías: Marielba Herrera Reina. 2011.

d) Festivos. Estos son los exvotos relacionados con danzas u ofrendas de palabra como pago por los favores recibidos. Claros ejemplos de ellos se ubican en la zona oriental, donde se realizan danzas en agradecimiento por salud, bienestar económico, viajes migratorios, lluvias y abundancia de las cosechas. Para último este caso, la Danza de los Tabales realizada a san Benito de Palermo, personaje que con el tiempo llegó a ser un icono del mulato campesino de la zona oriental del país, en la que los que obtienen el milagro de las lluvias y las cosechas están comprometidos a bailar al menos una vez al año esa danza, porque este pago es el reconocimiento del milagro de la abundancia. También, el mismo santo negro es buscado para sanar a la población infantil de enfermedades propias de la edad, entre otras peticiones que le hacen. Esto adquiere una connotación no tan sagrada como las otras, pues esta se realiza a las afueras de la iglesia, en donde las personas se reúnen para bailar al ritmo de instrumentos de cuerda. Otro ejemplo son las "ofrendas de palabra", en las que, en una fecha especial, son llevadas al santo invocado para recibir los favores solicitados. Este tipo de exvoto, hasta el año 2011, solamente se ha registrado en la zona oriental. Sin embargo, esto no quiere decir que este tipo de expresión religiosa popular no se esté practicando en otros lugares de las diferentes zonas del país.

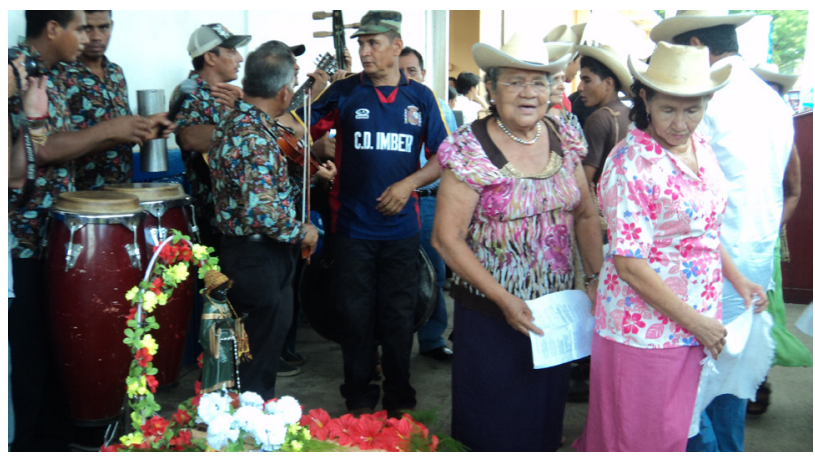

Danza de los Tabales se realiza por petición por la buena cosecha y como agradecimiento por los milagros recibidos y ofrendas de palabra a San Benito de Palermo. Ereguayquín.

Fotografías: Marielba Herrera Reina. 2012. 
e) Orales. Estos se refieren a los que se realizan en fiestas dedicadas a los patronos de los pueblos y ciudades. Entre ellos, se realizan rezos, misas y novenarios. Si bien estos no son parte de una expresión material, son muy comunes en el país, sobre todo cuando están relacionados con una catástrofe natural. En ese sentido, se pueden identificar muchas "misas juradas" o "novenarios jurados", que abarcan poblaciones enteras y que se transmiten de generación en generación. Un ejemplo de ello es la "Jura a la Virgen del Rosario", en el occidente del país, que tiene que ver con la peste de cólera morbo que afectó al país a finales del siglo XIX, en la que se le pidió que no siguiera afectando a Nahuizalco. Desde entonces, cada mes de octubre se sigue jurando la misa.

f) Mágicos. Estos son el resultado de la fusión de creencias y prácticas de magia y cristianismo. También se generan en sectores subalternos. Están orientados a patronos populares como Macario Canizález, Trema Adonai, el Hermano Simón, entre otros, que han surgido un contexto social similar como personajes que beneficiaban a su comunidad y que con el correr del tiempo llegaron a convertirse en patronos populares a los que les rinden cultos particulares. Estos se realizan en santuarios asignados por sus creyentes; pueden ser templos o tumbas, tal como se registró con el santo popular Macario Canizáles, para el que los agradecimientos pueden ser: la serenata que ofrecen y las ofrendas como puros, alcohol, comida, flores y velas, por mencionar algunos ejemplos.

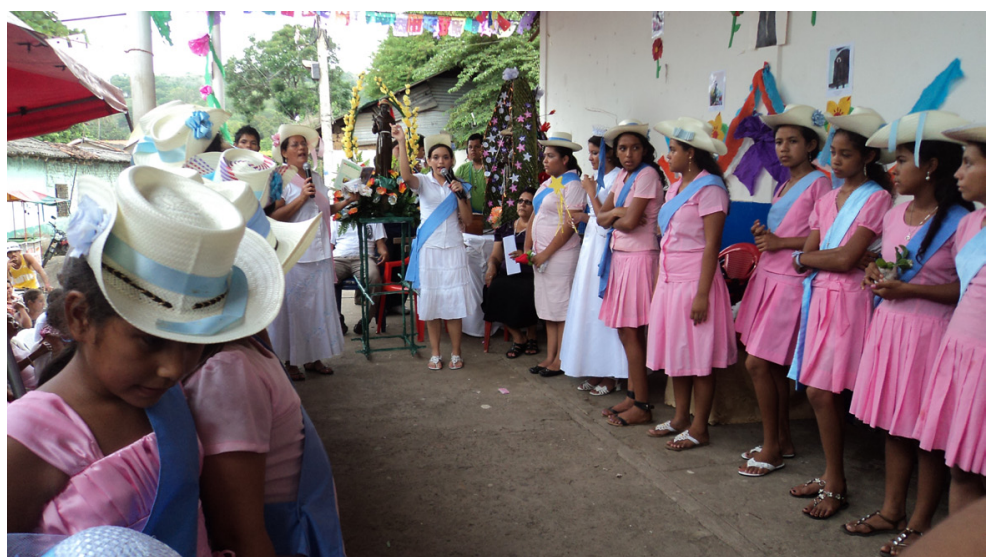

Ofrendas de puros y flores en la tumba de Macario Canizález. Fotografías: José Heriberto Erquicia. 2010.

\section{Significados diversos: expresiones de fe}

Estas expresiones tienen un valor histórico y cultural, en el que se reflejan condiciones de vida; ofrecen un testimonio muy valioso para el conocimiento de la historia, la cultura y la religiosidad popular del lugar donde se ubican; trasmiten información sobre creencias y prácticas que entrarían dentro del imaginario colectivo en la búsqueda del bienestar físico y social (Castilla, 2011). Ya sea de una forma u otra, el exvoto socializa "los temores, las carencias, las penurias y los posibles modos de solución que forman parte cotidiana de la vida de las clases subalternas y, asimismo, permite proyectar 
las aspiraciones y utopías concretas de tales clases” (González, 1996). Es decir, que generalmente van a estar asociados a los sectores populares más bajos; y se adquieren las especificaciones de lo divino y humano como objetos de poder sagrado, porque son las clases dominadas y subalternas de la sociedad las que compran o materializan estos objetos, que son colocados en los santuarios donde pueden encontrar a los santos o las imágenes de las que son creyentes.

En el caso de El Salvador, no se encuentran datos de cómo y cuándo aparecen estas representaciones comunicativas de poder con la divinidad. Sin embargo, existen registros de milagros de sanaciones relacionadas con el Señor de Esquipulas desde la época colonial. Posteriormente, en documentos eclesiásticos hay alusiones a milagros colectivos como los expuestos en el tipo de exvoto oral. Según algunas entrevistas realizadas, se menciona que anteriormente, quizá hace unos 50 años, sí existían exvotos pictóricos o retablos pequeños como los que se encuentran en México o Guatemala, que ofrecían una imagen en láminas metálicas de forma visual y escrita de los milagros recibidos.

González (1996) afirma que "lo que se desea en los exvotos populares es siempre un objeto o valor concreto, ligado a la subsistencia social y biológica elemental (cosechas, trabajo, salud, animales, libertad física, etc.) y a la vida cotidiana del pueblo/clases". Cada una de las peticiones está siendo abordada desde lo cotidiano, desde lo individual a lo colectivo; los espacios para desarrollar estas expresiones deben ser establecidos por los creyentes, con los materiales que ellos crean convenientes para realizar el pago humano en el universo del comercio divino.

Dentro de esa concepción, la relación con el santo elegido por los milagros que antes han recibido adquiere una connotación no solo divina, sino humana. En ese sentido, el devoto debe estar pendiente de la complacencia al santo; tener mucho cuidado de no molestarlo. Por ello, se le debe pedir permiso para obtener el favor o milagro de otro santo, para que los celos de este no le niegue futuras ayudas solicitadas. En este caso, se puede mencionar a san Judas Tadeo. Quienes lo veneran, deben acudir a él porque es el santo de las causas perdidas. Si su devoto busca a otro santo, debe pedir permiso para que los celos no lo alejen nunca y pueda seguir pidiéndole ayuda cuando lo necesite.

Otro caso es el de san Benito de Palermo, en el que cuentan sus creyentes que si no se realiza la Danza de los Tabales como se le prometió no hay buenas cosechas en ese año; o si es algo más personal, quien no danza está predispuesto a que sufra de temperatura alta como castigo por haberse negado o por haber incumplido la promesa.

De una u otra forma, las expresiones sociales, culturales, económicas y religiosas del mundo subalterno están presentes en la religiosidad popular. El estudio de la fenomenología permite trascender lo que a simple vista podría tratarse de un pago por algo recibido. En este caso, la cercanía de los mundos sagrado y profano abre un espacio próximo a los discursos y lenguajes empleados ante un momento de crisis, del tipo que sea; pero que genera un intercambio simbólico entre el ser humano y la divinidad. Esto implica una promesa que se debe cumplir, para que, si el petidor vuelve a necesitarle, 
esté a disposición de lo que solicite, pues anteriormente esa deuda ya fue saldada por el intercesor o la imagen seleccionada por el creyente, pues al final se resume en una condición de fe, donde creer permite tener acceso a un comercio sagrado y personal que solventa las necesidades materiales o espirituales de los males que los aquejan.

\section{CUADRO RESUMEN DE TIPOLOGÍA DE EXVOTOS PARA EL SALVADOR}

\begin{tabular}{|c|c|}
\hline Tipos & Descripción \\
\hline Milagritos & $\begin{array}{l}\text { Son producidos con cera o metal, generalmente } \\
\text { son partes anatómicas (brazos, cabezas, piernas, } \\
\text { manos) o figuras humanas (cuerpo entero), casas, } \\
\text { animales, vegetales, vehículos, entre otros. }\end{array}$ \\
\hline Resignificados & $\begin{array}{l}\text { Son de diversos materiales, que varían de formas y } \\
\text { tamaños, entre ellos, diplomas o títulos (por logros } \\
\text { académicos), de gorras, camisetas deportivas, } \\
\text { ramos de quinceañeras o novias (por alianzas } \\
\text { matrimoniales o cumplimiento de los quince } \\
\text { años de edad), ramos de flores plásticas, muletas } \\
\text { o aparatos ortopédicos o médicos, yesos, vendas } \\
\text { elásticas (por sanaciones) }\end{array}$ \\
\hline Discursivos & $\begin{array}{l}\text { Son escritos o gráficos realizados en una base de } \\
\text { papel, mármol, plástico o resina. }\end{array}$ \\
\hline Festivos & $\begin{array}{l}\text { Se refiere a danzas u ofrendas de palabra como } \\
\text { pago por los favores recibidos. }\end{array}$ \\
\hline Orales & $\begin{array}{l}\text { Expresiones realizadas en fiesta dedicadas a los } \\
\text { patronos de los pueblos y ciudades, entre ellos, } \\
\text { rezos, misas y novenarios, "misas juradas" o } \\
\text { "novenarios jurados", entre otros. }\end{array}$ \\
\hline Mágicos & $\begin{array}{l}\text { Se generan a partir de la fusión de creencias y } \\
\text { prácticas de magia y cristianismo, estos pueden } \\
\text { ser serenatas que ofrecen a los patronos y santos, } \\
\text { así como ofrendas como puros, alcohol, comida, } \\
\text { flores y velas. }\end{array}$ \\
\hline
\end{tabular}

\section{Referencias bibliográficas}

Castilla V, C. "Rezar para sanar: el recurso mágico-religioso en la búsqueda de la salud". Revista de Humanidades, 18, p. 109 - 124. España. 2011.

Fernández P, A. "La religiosidad popular en la globalización. Anales de antropología”. No. 43. Unam. México. 2009. 
García C, A. "Exvotos. El arte religioso popular. Acali”. Barcelona. 2011.

González, A. "Exvotos y retablitos. Religión popular y comunicación social en México. Estudios sobre las Culturas Contemporáneas”. México. 1986.

González, A. "Una mirada oblicua a la religión popular en México: retablos y santuarios entre la cultura y el poder". Cuadernos de Mass culturas. Universidad Iberoamericana León. México. 1996.

Roselló, E. "La cofradía de negros: una ventana a la tercera raíz". El caso de San Benito de Palermo, México: Tesis de Licenciatura para la Facultad de filosofía y Letras de la UNAM. 1998.

Sarnago, E. "Promesas y ofrendas religiosas: los exvotos". En Diccionario de Mitos y Leyendas. Equipo NAyA. Consultado en: http://www.cuco.com.ar/. 2011. 


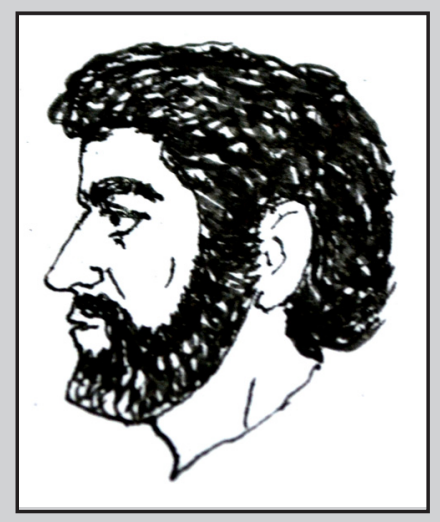

